\title{
EFEITOS DE PARÂMETROS DE EXTRUSÃO NAS PROPRIEDADES FÍSICAS DE PRODUTOS EXPANDIDOS DE INHAME ${ }^{1}$
}

\author{
Magali LEONEL ${ }^{2}, *$, Martha Maria MISCHAN ${ }^{3}$, Sheila Zambello de PINHO, \\ Ricardo António IATAURO ${ }^{4}$, Jaime DUARTE FILHO ${ }^{5}$
}

\begin{abstract}
RESUMO
Neste trabalho, estudou-se o efeito de parâmetros de extrusão sobre o índice de expansão (IE), volume específico (VE), índice de absorção de água (IAA) e índice de solubilidade em água (ISA) de extrusados de inhame. O processamento foi executado em extrusor mono rosca. Para analisar o efeito combinado das variáveis independentes nas características tecnológicas dos extrusados de farinha de inhame, utilizou-se o delineamento 'central composto rotacional' para três fatores. O desenho experimental foi elaborado para verificar o efeito de três níveis de temperatura na última zona de extrusão $\left(100,115\right.$ e $\left.130^{\circ} \mathrm{C}\right)$, rotação da rosca ( 163,204 e 245 $\mathrm{rpm}$ ) e umidade das farinhas $(12,15$ e 18\%). Os resultados obtidos mostraram que a umidade e a temperatura influenciaram os parâmetros de expansão (IE e VE). O índice de solubilidade em água (ISA) foi dependente dos três parâmetros do processo. Temperatura elevada e alta rotação da rosca promoveram maiores valores de ISA. Nas condições estudadas, os parâmetros de extrusão não influenciaram o índice de absorção de água (IAA).

Palavras-chave: Dioscorea alata, expansão, farinha, amido.
\end{abstract}

\section{SUMMARY}

EFFECT OF EXTRUSION PARAMETERS IN THE PHYSICAL PROPERTIES OF EXPANDED YAM SNACKS. Effect of extrusion parameters was studied on the expansion index, specific volume, water absorption index (WAI) and water solubility index (WSI) of expanded yam snacks. The central composite design was used to study the parameters effect. It was verified three levels of temperature in the barrel $\left(100,115\right.$ and $\left.130^{\circ} \mathrm{C}\right)$, three levels of screw speed $(163,204$ and $245 \mathrm{rpm}$ ) and three levels of flour moisture (12, 15 and 18\%). The results showed that expansion properties (expansion index and specific volume) depend on flour moisture and extrusion temperature. The WSI was dependant of three parameters. Higher levels of temperature and screw speed increase the water solubility index (WSI). The studied parameters did not influence the water absorption index (WAI).

Keywords: Dioscorea alata, expansion, flour, starch.

\section{1- INTRODUÇÃO}

A cultura do inhame (Dioscorea ssp.) está presente em várias partes do mundo, mas a grande maioria das espécies cultivadas procede originalmente das zonas tropicais da Ásia e do Oeste da África. O inhame é uma planta monocotiledônea, herbácea, trepadeira, de clima tropical e subtropical. Seus tubérculos são ricos em carboidratos e vitaminas do complexo $\mathrm{B}$, além de encerrar teores das vitaminas A e C [9].

No Brasil, a Paraíba é o Estado de maior produção ( 17.800 t) numa área de 4.300 hectares (ha), com produtividade média de 4,2 t/ha. O Estado de São Paulo apresenta baixa expressão na produção nacional dessa cultura $(317,4$ ha com $2.600 \mathrm{t}$ ), porém apresenta a maior produtividade média $(9,0$ t/ha) [11].

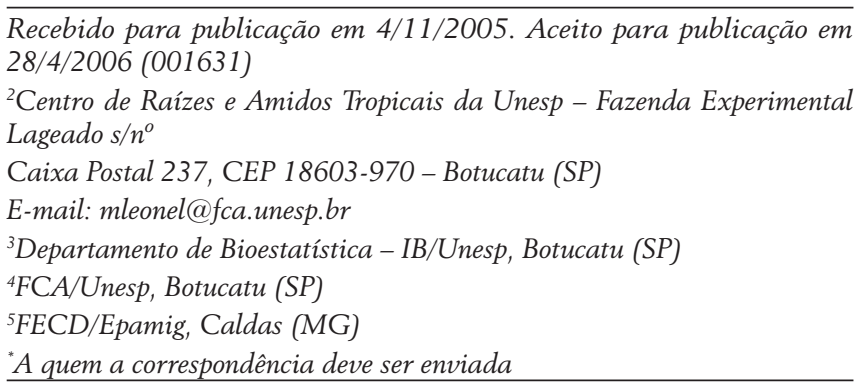

Quanto às cultivares, SANTOS [11], em sua revisão, relata que no Brasil, notadamente na Região Nordeste, são plantadas as cultivares Da Costa e Tabica, procedentes de Pernambuco, e Espinho Freire e Negro, procedentes do Instituto Agronômico de Campinas, todas classificadas na espécie Dioscorea cayennensis. Em São Paulo, a principal cultivar é Flárida, que pertence à espécie Dioscorea alata L., que se caracteriza pela casca marrom-clara, polpa granulosa, conformação alongada (quase cilíndrica) dos rizomas, com bom aspecto comercial para as exigências do mercado paulista [9].

O desenvolvimento de produtos alimentícios tendo como base raízes tropicais, de tradição de cultivo e apelo cultural como o inhame, tem obtido o interesse dos produtores rurais e industriais, pois possibilitaria o incremento de toda a cadeia produtiva.

A tecnologia de extrusão, nos últimos tempos, tem se tornado um dos principais processos no desenvolvimento de produtos. O processo de extrusão permite produzir modificações pela compressão da matéria-prima amilácea. Esta é forçada contra uma matriz ou molde, em condições de mistura, aquecimento e pressão, que levam à gelificação do amido.

O controle do processo de extrusão permite a obtenção de produtos com características variadas, melhndo 
a eficiência e economia da operação. Embora a extrusão seja um processo tecnológico simples, seu controle é complexo, devido ao grande número de variáveis envolvidas no processo e sua complexidade. O controle das condições de extrusão tais como temperatura, taxa de compressão da rosca, taxa de alimentação, teor de umidade e componentes de alimentação, é essencial para garantir a boa qualidade do produto e evitar perdas de nutrientes [4].

Tendo em vista a importância da cultura do inhame no País, a necessidade de introdução desta raiz como matéria-prima industrial para a ampliação do cultivo com maior rentabilidade e as vantagens da tecnologia de extrusão no desenvolvimento de produtos alimentícios, este trabalho teve por objetivo avaliar o efeito da umidade da farinha, rotação da rosca e temperatura de extrusão nas características físicas extrusados de farinha de inhame (Dioscorea alata).

\section{2 - MATERIAL E MÉTODOS}

\section{1 - Produção e caracterização da farinha de inhame}

Os rizomas de inhame foram plantados na Fazenda Experimental Lageado, em Botucatu (SP). O clima é definido, de acordo com a classificação Koeppen, como Csa ou temperado chuvoso, úmido e com verões quentes. A precipitação média anual na região é de $1.517 \mathrm{~mm}$ e a temperatura média anual de $20,6^{\circ} \mathrm{C}$. O plantio foi realizado em outubro de 2003 e a colheita em outubro de 2004.

Para a produção da farinha, foram processados $200 \mathrm{Kg}$ de inhame seguindo as etapas de descascamento manual, lavagem em água corrente, corte em fatiador de frios, desidratação em estufa de circulação de $\operatorname{ar}\left(45^{\circ} \mathrm{C}\right)$, moagem em moinho de facas e embalagem para armazenamento.

Na caracterização química da farinha de inhame o teor de umidade foi determinado usando-se estufa com circulação de ar a $105^{\circ} \mathrm{C}$ por $8 \mathrm{~h}$ [3]. Para a determinação do teor de cinzas, utilizou-se mufla a $550^{\circ} \mathrm{C}$ por $2 \mathrm{~h}$ [3].

A análise do teor de fibra bruta foi feita através de digestão do material em solução de $\mathrm{H}_{2} \mathrm{SO}_{4}$ a $1,25 \% \mathrm{p} / \mathrm{v}$ por 30 min a temperatura de $98^{\circ} \mathrm{C}$, seguida de $\mathrm{NaOH} 1,25 \% \mathrm{p} / \mathrm{v}$ por mais 30 min na mesma temperatura [3].

A determinação do teor de matéria graxa foi realizada em extrator Soxhlet completo, utilizando-se éter de petróleo para a extração [3].

Para a avaliação do teor de proteína da farinha, utilizouse destilador micro-Kjeldahl e bloco digestor, avaliando-se a porcentagem de nitrogênio $(\mathrm{N})$ na amostra. A conversão para proteína foi feita por $\mathrm{N}$ x 6,25 [3].

O teor de amido foi determinado a partir da hidrólise enzimática de acordo com RICHARD \& BENH [10] e o teor de açúcares dosado segundo SOMOGY [13].

\section{2 - Processo de extrusão}

A extrusão foi efetuada em uma linha completa de extrusão IMBRA RX da Imbramaq S/A com motor de 10HP acoplado a redutor de velocidade, sistema de extrusão através de fricção mecânica, rosca simples de extrusão, sistema de refrigeração hidráulica para controle de temperatura na camisa de extrusão, velocidade variável e capacidade de produção de $45 \mathrm{~kg} / \mathrm{h}$.

Os parâmetros de processamento foram divididos em parâmetros fixos e variáveis. Os parâmetros fixos foram:

- Taxa de compressão da rosca: 3:1

- Taxa de alimentação (g/min): 200 g/min

- Abertura da matriz (mm): $3 \mathrm{~mm}$

- Temperatura na $1^{\mathrm{a}}$ zona de aquecimento do extrusor: $20^{\circ} \mathrm{C}$

- $\quad$ Temperatura na $2^{\mathrm{a}}$ zona de aquecimento do extrusor: $70^{\circ} \mathrm{C}$

Os parâmetros variáveis foram: temperatura na $3^{\mathrm{a}}$ zona de aquecimento do extrusor, umidade das farinhas e rotação da rosca, avaliados em três níveis (Tabela 1).

\section{3 - Análises dos extrusados}

\subsection{1 - Índice de expansão}

O índice de expansão dos extrusados foi avaliado no material após a extrusão e antes da secagem. Foi calculado pela relação entre o diâmetro da amostra e o diâmetro da matriz, conforme a metodologia proposta por FAUBION \& HOSENEY [7]. O valor considerado foi obtido pela média aritmética das medidas de 15 diferentes produtos expandidos dentro de cada tratamento.

\subsection{2 - Volume específico}

O volume específico dos produtos expandidos foi determinado pelo método do deslocamento da massa ocupada (semente de painço) e determinado o seu volume em uma proveta graduada. Para o cálculo utilizou-se a Equação (1):

$$
\mathrm{VE}=\mathrm{v} / \mathrm{p}
$$

Onde:

VE - volume específico ( $\mathrm{mL} / \mathrm{g})$

$\mathrm{p}-$ peso (g)

$\mathrm{v}$ - volume $(\mathrm{mL})$

\subsection{3 - Índice de absorção de água (IAA)}

$\mathrm{O}$ IAA foi determinado segundo metodologia de AN- 
DERSON et al. [2]. Em um tubo de centrífuga, previamente tarado, foram colocados aproximadamente $2,5 \mathrm{~g} \mathrm{de}$ amostra e $30 \mathrm{~mL}$ de água. Os tubos foram agitados por 30 min em agitador mecânico e, em seguida, centrifugados a $3.000 \mathrm{rpm}$ por $10 \mathrm{~min}$, em centrífuga Excelsa Baby II, de marca Fanem, modelo 206-R. Do líquido sobrenadante, 10 $\mathrm{mL}$ foram transferidos cuidadosamente para cadinho de porcelana previamente tarado. O material remanescente foi pesado e o IAA calculado conforme a Equação (2):

$\mathrm{IAA}=\mathrm{PRC} / \mathrm{PA}-\mathrm{PRE}$

Onde:

IAA - índice de absorção de água (g gel/g de matéria seca)

PRC - peso do resíduo de centrifugação (g)

PA - peso da amostra (g) (base seca)

PRE - peso do resíduo de evaporação (g)

\subsection{4 - Índice de solubilidade em água (ISA)}

O ISA, determinado segundo metodologia de ANDERSON et al. [2], foi calculado pela relação entre o peso do resíduo da evaporação e o peso seco da amostra, conforme a Equação (3):

$\mathrm{ISA}=\mathrm{PRE} / \mathrm{PA}^{*} 100$

Onde:

ISA - índice de solubilidade em água (\%)

PA - peso da amostra (g) (base seca)

PRE - peso do resíduo de evaporação (g)

\section{4 - Delineamento experimental e análise estatística}

Para analisar o efeito combinado das variáveis independentes nas características tecnológicas dos extrusados de farinha de inhame utilizou-se o delineamento 'central composto rotacional' para três fatores, segundo COCHRAN \& COX [5], com um total de 15 tratamentos, a saber:

- Oito tratamentos correspondentes ao fatorial $2^{3}$, onde os três fatores são:

$\mathrm{R}$ - rotação (rpm), T - temperatura $\left({ }^{\circ} \mathrm{C}\right), \mathrm{U}$ - umidade (\%); cada qual em dois níveis, codificados como -1 e +1
- $\quad$ seis tratamentos com níveis mínimo e máximo de cada fator, codificados como $-\alpha \mathrm{e}+\alpha$, respectivamente, sendo $\alpha=2^{3 / 4}=1,682$;

- Um tratamento central repetido seis vezes, no qual os fatores estão todos em um nível médio, codificado como zero.

TABELA 1 - Níveis dos fatores rotação (R), temperatura (T) e umidade (U) e os correspondentes níveis codificados (X)

\begin{tabular}{lccccc}
\hline $\mathbf{X}$ & $-\boldsymbol{\alpha}=-\mathbf{1 , 6 8 2}$ & $\mathbf{- 1}$ & $\mathbf{0}$ & $\mathbf{1}$ & $\mathbf{\alpha}=\mathbf{1 , 6 8 2}$ \\
\hline $\mathrm{R}(\mathrm{rpm})$ & 136 & 163 & 204 & 245 & 272 \\
$\mathrm{~T}\left({ }^{\circ} \mathrm{C}\right)$ & 90 & 100 & 115 & 130 & 140 \\
$\mathrm{U}(\%)$ & 10 & 12 & 15 & 18 & 20 \\
\hline
\end{tabular}

Para a análise estatística dos resultados experimentais utilizou-se o modelo (Equação 4):

$$
y_{k}=b_{0}+\sum_{i=1}^{3} b_{i} x_{i k}+\sum_{i=1}^{3} \sum_{j=i}^{3} b_{i j} x_{i k} x_{j k}+e_{k},
$$

Onde

$\mathrm{y}_{\mathrm{k}}$ - valor observado da variável dependente no nível $k, \mathrm{k}=1, \ldots, 20$;

$\mathrm{x}_{\mathrm{ik}}$ - i-ésima variável independente, no nível $k, \mathrm{i}=1$, 2,3

$\mathrm{b}_{0}$ - parâmetro do modelo, independente de $x$;

$\mathrm{b}_{\mathrm{i}}$ - parâmetros correspondentes aos efeitos lineares de $x_{i}$;

$b_{i j}$ - parâmetros correspondentes aos efeitos de $2^{a}$ ordem de $x_{i} x_{j}, i=1,2,3, j=i, \ldots, 3$;

$\mathrm{e}_{\mathrm{k}}$ - erro experimental associado à k-ésima parcela.

\section{3 - RESULTADOS E DISCUSSÃO}

Os resultados obtidos na caracterização química da farinha de inhame mostraram que a farinha é predominantemente amilácea, mas apresenta em sua composição consideráveis teores de proteínas e fibras e baixo conteúdo de lipídeos (Tabela 2).

Na Tabela 3, estão apresentados os níveis codificados e valores reais dos parâmetros de extrusão, bem como os resultados encontrados para as variáveis dependentes nos diferentes tratamentos.

TABELA 2 - Composição química da farinha de inhame

\begin{tabular}{lc}
\hline Composição $\mathbf{( g / 1 0 0 ~} \mathbf{g})$ & Média \\
\hline Umidade & $6,2 \pm 0,04$ \\
Cinzas & $2,21 \pm 0,03$ \\
Amido & $74,67 \pm 0,06$ \\
Fibras & $3,96 \pm 0,14$ \\
Proteínas & $5,81 \pm 0,03$ \\
Lipídeos & $0,39 \pm 0,01$ \\
Açúcares totais & $6,7 \pm 0,08$ \\
\hline
\end{tabular}


A partir dos dados obtidos na caracterização dos extrusados foram elaborados modelos matemáticos de regressão que expressam a relação entre as condições empregadas e os valores obtidos para índice de expansão, volume específico, índice de solubilidade em água e índice de absorção de água dos extrusados após os tratamentos (Tabela 4).

O modelo de regressão adotado para índice de expansão (IE) não foi significativo $(p>0,05)$. Dentre os fatores que compõem o modelo a temperatura $(p=0,022)$ afetou significativamente o IE, ao passo que não foi observado o efeito significativo da umidade $(p=0,056)$ e da rotação da rosca $(p=0,489)$. O coeficiente de determinação $\left(\mathrm{R}^{2}\right)$ foi de $71,2 \%$.

A análise do efeito da temperatura de extrusão ( $F i$ gura 1) mostrou que o aumento deste fator levou a uma diminuição do índice de expansão dos extrusados de inhame. Os maiores valores foram obtidos em condições de baixa temperatura.
Resultados semelhantes foram observados por ALVES \& GROSSMAN [1], que observaram maior expansão em extrusados de Dioscorea alata com valores de umidade e temperatura baixos. Os níveis de umidade utilizados foram de 16 a $24 \%$ e temperatura de 120 a $180^{\circ} \mathrm{C}$.

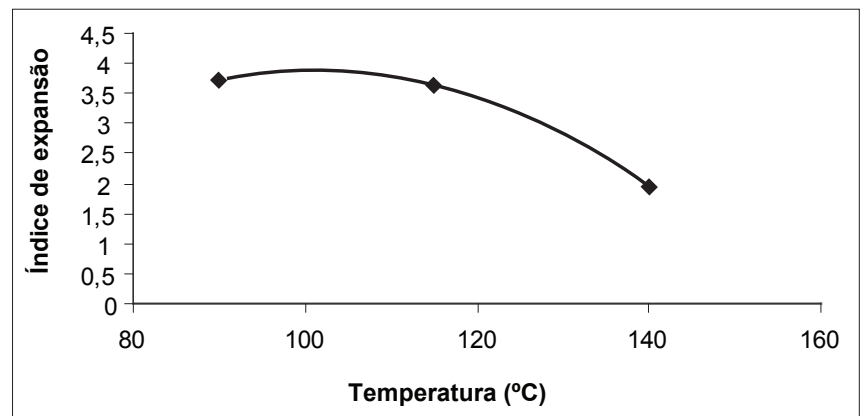

FIGURA 1 - Efeito da temperatura de extrusão no índice de expansão dos extrusados de inhame, sob rotação de $204 \mathrm{rpm}$ e umidade de $15 \%$

TABELA 3 - Valores médios do índice de expansão (IE), volume específico (VE), índice de solubilidade em água (ISA) e índice de absorção de água (IAA) dos extrusados de inhame, segundo o delineamento fatorial

\begin{tabular}{|c|c|c|c|c|c|c|c|c|c|c|}
\hline \multirow[b]{2}{*}{ Tratamentos } & \multicolumn{6}{|c|}{ Parâmetros de extrusão } & \multirow{2}{*}{\multicolumn{4}{|c|}{ Variáveis dependentes }} \\
\hline & \multicolumn{3}{|c|}{ Variáveis codificadas } & \multicolumn{3}{|c|}{ Variáveis independentes } & & & & \\
\hline 1 & $\begin{array}{ll}-1 \\
\end{array}$ & -1 & -1 & 163 & 12 & 100 & 3,81 & 7,87 & 54,01 & 7,49 \\
\hline 3 & -1 & 1 & -1 & 163 & 18 & 100 & 2,98 & 3,72 & 52,02 & 7,33 \\
\hline 4 & 1 & 1 & -1 & 245 & 18 & 100 & 3,3 & 1,67 & 56,59 & 7,96 \\
\hline 5 & -1 & -1 & 1 & 163 & 12 & 130 & 3,94 & 4,79 & 52,54 & 7,36 \\
\hline 8 & 1 & 1 & 1 & 245 & 18 & 130 & 3,03 & 4,46 & 55,89 & 7,65 \\
\hline 9 & 0 & 0 & 0 & 204 & 15 & 115 & 3,83 & 7,15 & 48,77 & 7,05 \\
\hline 10 & 0 & 0 & 0 & 204 & 15 & 115 & 3,73 & 6,84 & 53,32 & 7,63 \\
\hline 11 & 0 & 0 & 0 & 204 & 15 & 115 & 3,10 & 7,04 & 51,41 & 7,17 \\
\hline 12 & 0 & 0 & 0 & 204 & 15 & 115 & 3,67 & 7,40 & 54,20 & 6,53 \\
\hline 17 & 0 & $-\alpha$ & 0 & 204 & 10 & 115 & 3,65 & 8,45 & 62,92 & 9,24 \\
\hline 18 & 0 & $+\alpha$ & 0 & 204 & 20 & 115 & 3,23 & 2,38 & 55,24 & 9,10 \\
\hline 19 & 0 & 0 & $-\alpha$ & 204 & 15 & 90 & 3,73 & 4,64 & 63,54 & 16,39 \\
\hline 20 & 0 & 0 & $+\alpha$ & 204 & 15 & 140 & 1,94 & 6,12 & 70,38 & 10,53 \\
\hline
\end{tabular}

TABELA 4 - Análises de variância das regressões, coeficiente de determinação $\left(R^{2}\right)$, modelos ajustados de $2^{\mathrm{a}}$ ordem para índice de expansão (IE), volume específico (VE), índice de solubilidade em água (ISA) e índice de absorção em água (IAA) dos extrusados

\begin{tabular}{|c|c|c|c|c|c|c|c|}
\hline \multirow{2}{*}{ Variável } & \multicolumn{6}{|c|}{ Análise de variância da regressão } & \multirow{2}{*}{ Modelo de regressão de $2^{\mathrm{a}}$ ordem $^{*}$} \\
\hline & GL & $S Q$ & QM & $F$ & p & $\mathbf{R}^{2}$ & \\
\hline IE & $\begin{array}{c}\text { Regressão } 9 \\
\text { Resíduo } 10\end{array}$ & $\begin{array}{l}3,016 \\
1,220\end{array}$ & $\begin{array}{l}0,335 \\
0,122\end{array}$ & 2,75 & 0,066 & 0,712 & $\mathrm{IE}=3,647-0,068 \mathrm{R}-0,204 \mathrm{U}-0,257 \mathrm{~T}+0,395 \mathrm{R}^{2}-0,056 \mathrm{U}^{2}-0,27 \mathrm{~T}^{2}+0,125 \mathrm{RU}-0,157 \mathrm{RT}+0,0575 \mathrm{UT}$ \\
\hline VE & $\begin{array}{c}\text { Regressão } 9 \\
\text { Resíduo } 10\end{array}$ & $\begin{array}{c}74,09 \\
6,89\end{array}$ & $\begin{array}{l}8,232 \\
0,689\end{array}$ & 11,95 & $<0,001$ & 0,915 & $V E=7,33+0,014 R-1,602 U+0,574 T-0,093 R^{2}-0,665 U^{2}-0,677 T^{2}-1,224 R U+0,37 R T+1,099 U T$ \\
\hline ISA & $\begin{array}{c}\text { Regressão } 9 \\
\text { Resíduo } 10\end{array}$ & $\begin{array}{l}749,2 \\
43,95\end{array}$ & $\begin{array}{c}83,25 \\
4,39\end{array}$ & 18,94 & $<0,001$ & 0,945 & ISA $=52,03+2,43 R-2,87 \mathrm{U}+2,535 \mathrm{~T}-0,546 \mathrm{R}^{2}+2,091 \mathrm{U}^{2}+4,879 \mathrm{~T}^{2}-0,386 \mathrm{RU}+0,529 \mathrm{RT}-2,836 \mathrm{UT}$ \\
\hline IAA & $\begin{array}{c}\text { Regressão } 9 \\
\text { Resíduo } 10\end{array}$ & $\begin{array}{l}60,72 \\
36,81\end{array}$ & $\begin{array}{l}6,75 \\
3,68\end{array}$ & 1,83 & 0,179 & 0,623 & IAA $=7,28+0,391 \mathrm{R}-0,37 \mathrm{U}-0,529 \mathrm{~T}-0,321 \mathrm{R}^{2}+0,219 \mathrm{U}^{2}+1,737 \mathrm{~T}^{2}-0,404 \mathrm{RU}+0,511 \mathrm{RT}-0,556 \mathrm{UT}$ \\
\hline
\end{tabular}

* Os parâmetros do modelo foram codificados de acordo com a Tabela 3

IE - índice de expansão; VE - volume específico (mL/g); ISA - índice de solubilidade em água (\%); IAA - índice de absorção em água (g/g gel), U - umidade das farinhas (\%), R - rotação da rosca $(\mathrm{rpm}), \mathrm{T}$ - temperatura na $3^{\circ}$ zona de extrusão $\left({ }^{\circ} \mathrm{C}\right)$ 
O modelo de regressão adotado para volume específico (VE) foi significativo $(\mathrm{p}<0,05)$. Dentre os fatores que compõem o modelo, a umidade $(\mathrm{p}<0,001)$ e a temperatura $(\mathrm{p}=0,029)$ afetaram significativamente o VE, ao passo que não foi observado o efeito significativo da rotação da rosca $(\mathrm{p}=0,952)$. O coeficiente de determinação múltipla $\left(\mathrm{R}^{2}\right)$ foi de $91,5 \%$.

A análise do efeito da umidade e da temperatura sobre o volume específico em rotação de 204 rpm mostrou que maiores valores de VE foram obtidos em condições de baixa umidade e temperatura (Figura 2).

De acordo com DING et al. [6], a água tem efeito inverso sobre a expansão, agindo como um plastificante para materiais amiláceos, reduzindo sua viscosidade e a dissipação da energia mecânica no extrusor e, assim, o produto fica mais denso e o crescimento das bolhas é comprimido.

O volume específico é um parâmetro primário, associado às medidas de fraturabilidade, dureza, absorção de água e solubilidade em água dos produtos produzidos por extrusão termoplástica. Está diretamente relacionado com a expansão (axial + radial) e negativamente correlacionado com a densidade [8].

Para o índice de solubilidade em água (ISA), o modelo de regressão foi significativo $(\mathrm{p}<0,05)$. Todos os fatores que compõem o modelo afetaram significativamente este índice, sendo o coeficiente de determinação de $94,5 \%$.

Os maiores valores de índice de solubilidade em água foram obtidos em condições de baixa umidade e temperatura, na rotação de 204 rpm (Figura 3), baixa rotação e umidade, em temperatura de $115^{\circ} \mathrm{C}$ (Figura 4) e alta temperatura e rotação da rosca, com umidade de 15\% (Figura 5).

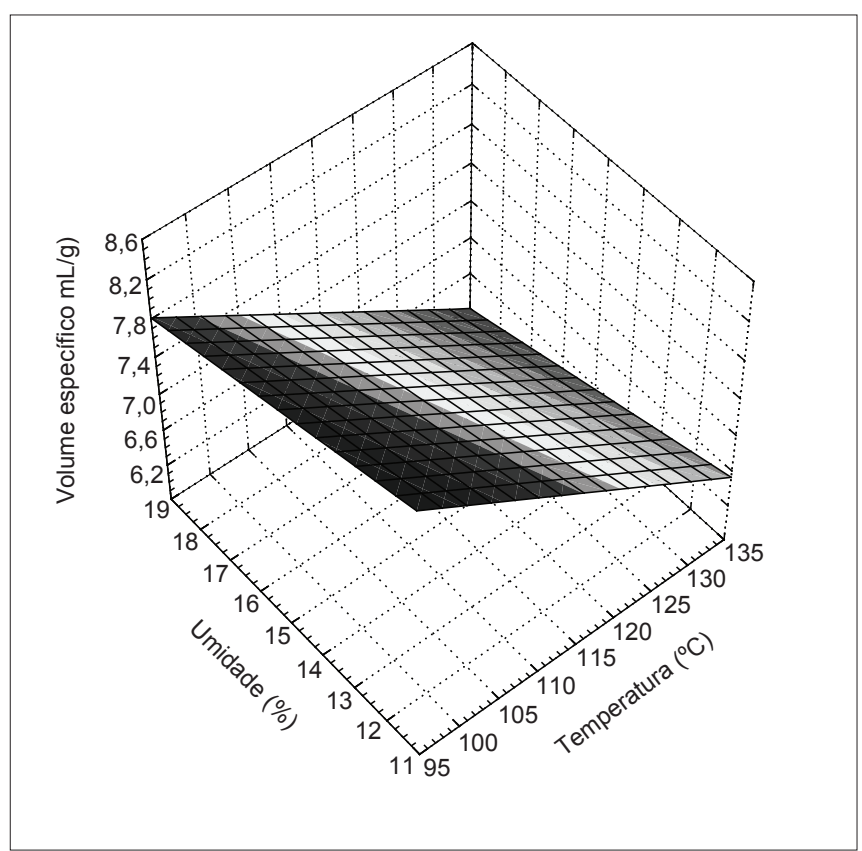

FIGURA 2 - Efeito da umidade das amostras e da temperatura de extrusão no volume específico dos extrusados de inhame, sob rotação de 204 rpm
Os valores observados foram superiores à média obtida na farinha de inhame antes da extrusão $(9,96 \%)$ e aos obtidos por SEBIO [12] em extrusados de Dioscorea rotundata, que variaram de 11 a $37 \%$ em condições de umidade de 15 a $28 \%$, temperatura 83 a $150^{\circ} \mathrm{C}$ e rotação da rosca de 66 a $234 \mathrm{rpm}$.

O índice de solubilidade em água é um parâmetro que reflete o grau de degradação do grânulo de amido, ou seja, a somatória dos efeitos de gelatinização, dextrinização e conseqüente solubilização.

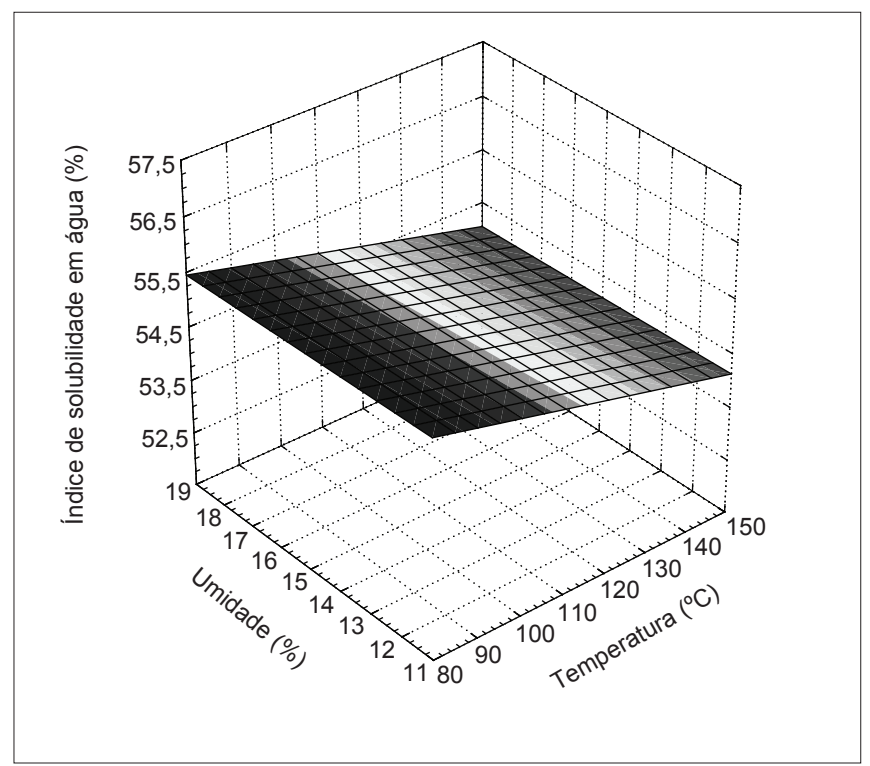

FIGURA 3 - Efeito da umidade das amostras e da temperatura de extrusão no índice de solubilidade em água dos extrusados de inhame, sob rotação de 204 rpm

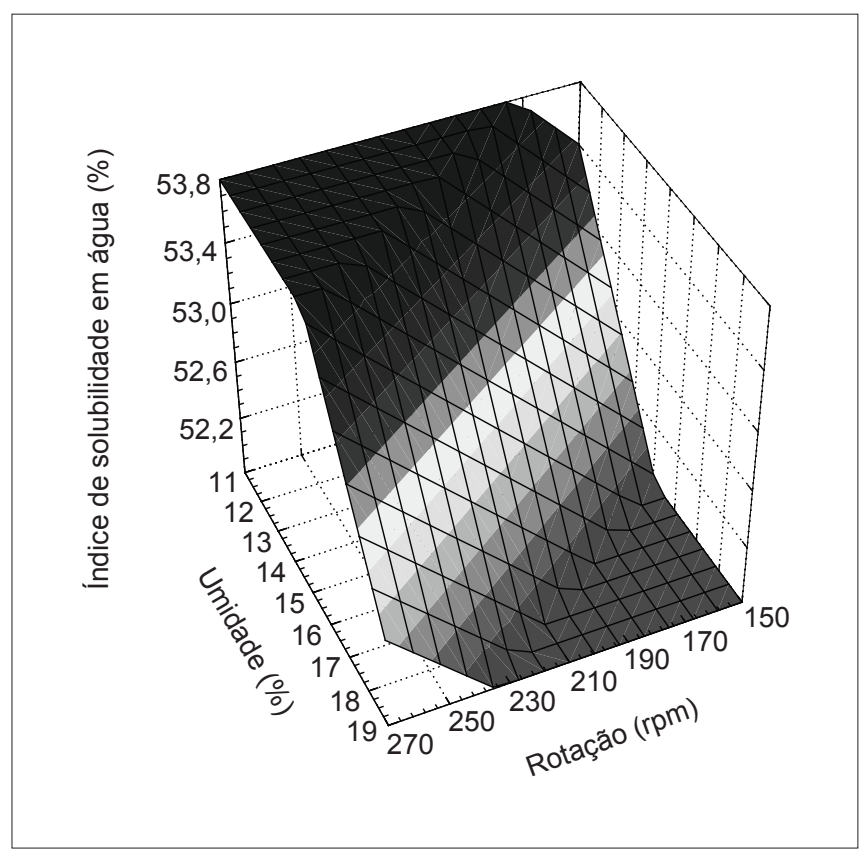

FIGURA 4 - Efeito da umidade das amostras e da rotação da rosca no índice de solubilidade em água dos extrusados de inhame, sob temperatura de $115^{\circ} \mathrm{C}$ 


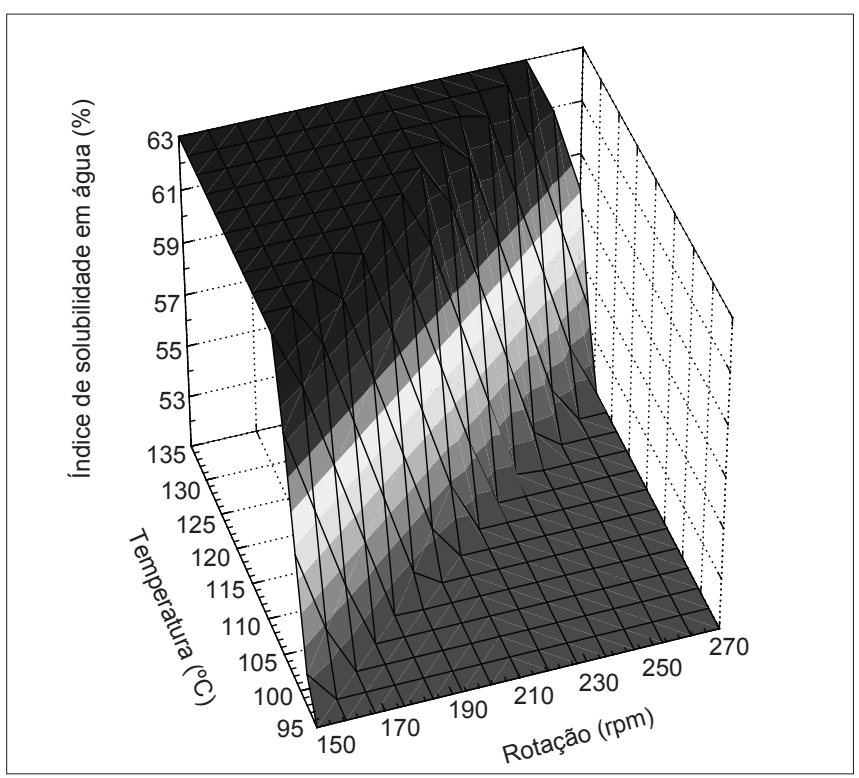

FIGURA 5 - Efeito da temperatura de extrusão e da rotação da rosca no índice de solubilidade em água dos extrusados de inhame, com $15 \%$ de umidade nas amostras

O modelo de regressão adotado para o índice de absorção de água (IAA) não foi significativo ( $p>0,05)$. $O$ coeficiente de determinação múltipla foi de $62,3 \%$. Não se observou efeito significativo dos fatores: umidade $(p=0,493)$, temperatura $(p=0,332)$ e rotação $(p=0,469)$, nos níveis estudados, sobre este índice.

Os valores de IAA variaram de 6,5 a 16,4 g/g gel, sendo que os menores valores foram observados em condições de alta umidade e temperatura. Estes valores foram superiores á média da farinha de inhame não extrusada, que foi de $3,03 \mathrm{~g} / \mathrm{g}$ gel.

O índice de absorção de água está relacionado com a disponibilidade de grupos hidrofílicos (-OH) em se ligar às moléculas de água e à capacidade de formação de gel das moléculas de amido. Somente os grânulos de amido gelatinizados absorvem água em temperatura ambiente e incham [4].

\section{4 - CONCLUSÕES}

De modo geral, pode-se concluir que os parâmetros, umidade, temperatura e rotação influem na qualidade dos extrusados de inhame, requerendo cuidados nos níveis aplicados.

A umidade e a temperatura influenciaram os parâmetros de expansão (IE e VE), sendo que níveis baixos destes parâmetros $\left(<15 \%\right.$ e $\left.115^{\circ} \mathrm{C}\right)$ implicam em maior expansão.

O índice de solubilidade em água (ISA) foi dependente dos três parâmetros do processo, com maior destaque para temperatura. Temperatura elevada $\left(>115^{\circ} \mathrm{C}\right)$ e alta rotação da rosca (>204 $\mathrm{rpm})$ promoveram maiores valores de ISA.

Nas condições estudadas os parâmetros de extrusão não influenciaram o índice de absorção de água.

\section{5 - REFERÊNCIAS BIBLIOGRÁFICAS}

[1] ALVES, R.M.L.; GROSSMANN, M.V.E. Parâmetros de extrusão para produção de snacks de farinha de cará (Dioscorea alata). Ciênc. Tecnol. Aliment., Campinas, v. 22, n. 1, p. 32-38, 2002.

[2] ANDERSON, R.A.; CONWAY, H.F.; PFEIFER, V.F.; GRIFFIN, L.Jr. Gelatinization of corn grits by roll and extrusion cooking. Cereal Science Today, v. 14, n. 1, p. 4-11, 1969.

[3] ASSOCIATION OF OFFICIAL ANALYTICAL CHEMISTS. Official methods of analysis., $13^{\text {th }} \mathrm{ed}$. Washington, 1980, 109 p.

[4] CARVALHO, R.V. Formulações de snacks de terceira geração por extrusão: caracterização texturométrica e microestrutural. Lavras (MG), 89 p., 2000. Dissertação (mestrado em Ciência dos Alimentos) - Universidade Federal de Lavras.

[5] COCHRAN, W.G.; COX, G.M. Experimental designs, $2^{\text {nd }}$ ed. New York: John Wiley \& Sons, Inc., 1957, 611 p.

[6] DING, Q.; AINSWORTH, P; TUCKER, G.; MARSON, H. The effect of extrusion conditions on the physicochemical properties and sensory characteristics of rice-based expanded snacks. Journal of Food Engineering, v. 66, p. 283-289, 2005.

[7] FAUBION, J.M., HOSENEY, R.C. High temperature and short time. Extrusion-cooking of wheat starch and flour. I - Effect of moisture and flour type on extrudate properties. Cereal Chemistry, v. 59, n. 6 , p. 529-533, 1982.

[8] KARAM, L.B.; GROSSMANN, M.V.E.; SILVA, R.S.S.F. Misturas de farinha de aveia e amido de milho com alto teor de amilopectina para produção de snacks. Ciência e Tecnologia de Alimentos, Campinas, v. 21, n. 2, p. 158-163, 2001.

[9] MONTEIRO, D.A. Situação atual e perspectivas do inhame no Estado de São Paulo. In: CARMO, C.A.S. do. Inhame e taro: sistema de produção familiar. Vitória: Incaper, 2002, p. 85-92.

[10] RICKARD, J.E.; BEHN, K.R. Evaluation of acid and enzyme hydrolitic methods for determination of cassava starch. J. Sci. Food Agric., v. 41, p. 373-379, 1987.

[11] SANTOS, E.S. dos. Manejo da cultura do inhame. In: CARMO, C.A.S. do. Inhame e taro: sistema de produção familiar. Vitória: Incaper, 2002, p. 253-279.

[12] SEBIO, L. Efeito de alguns parâmetros operacionais de extrusão nas propriedades físico-químicas da farinha de inhame (Dioscorea rotundata). Campinas, 1996. Dissertação (mestrado) - Faculdade de Engenharia de Alimentos, Universidade Estadual de Campinas.

[13] SOMOGY, M. Determination of blood sugar. J. Biol. Chem., n. 160, p. 69-73, 1945. 